\title{
The subterranean fauna of Barrow Island, north-western Australia: 10 years on
}

\author{
Garth Humphreys ${ }^{1,2,3,8}$, Jason Alexander ${ }^{1}$, Mark S. Harvey ${ }^{2,3,4,5,6}$ \\ and William F. Humphreys $\mathrm{s}^{2,3,7}$
}

\author{
${ }^{1}$ Biota Environmental Sciences Pty Ltd, PO Box 155, Leederville, Western Australia 6903, Australia. \\ ${ }^{2}$ Department of Terrestrial Zoology, Western Australian Museum, Locked Bag 49, Welshpool DC, \\ Western Australia 6986, Australia. \\ ${ }^{3}$ School of Animal Biology, University of Western Australia, Crawley, Western Australia 6009, Australia. \\ ${ }^{4}$ Division of Invertebrate Zoology, American Museum of Natural History, \\ 79th Street at Central Park West, New York, New York 10024-5192, U.S.A. \\ ${ }^{5}$ Department of Entomology, California Academy of Sciences, Golden Gate Park, \\ San Francisco, CA 94103-3009, U.S.A. \\ ${ }^{6}$ School of Natural Sciences, Edith Cowan University, Joondalup, Western Australia 6009, Australia. \\ ${ }^{7}$ School of Earth and Environmental Sciences, University of Adelaide, South Australia 5005, Australia \\ ${ }^{8}$ Corresponding author: Email: garth@biota.net.au
}

\begin{abstract}
Barrow Island, situated off the north-west Australian coast, is well recognised for its subterranean fauna values. Sampling for both stygobitic and troglobitic fauna has taken place on the island since 1991, and Humphreys (2001) summarised the then current state of knowledge of the island's subterranean fauna. Sampling for impact assessment purposes on the island over the past decade has substantially increased the recorded species richness of Barrow Island. The number of documented stygal taxa has more than doubled since 2001, from 25 to 63 species now known. Troglobitic diversity has also substantially increased, with six species known in 2001 and 19 troglobitic taxa known today. The total recorded subterranean species richness for Barrow Island at this time stands at 82 species. It is likely that considerably more species remain to be recorded, as even the additional surveys of the past decade leave many areas of the island unsampled.
\end{abstract}

The distributions and minimum area of occupancy for many species known from Barrow Island in 2001 have also been significantly expanded by the sampling efforts of the last decade. This includes specially protected species listed under State and Commonwealth Government legislation. The available data suggest the fauna of the island may number in the hundreds of species, many of which are endemic, confirming its status as internationally significant for subterranean biota.

KEYWORDS: stygofauna, troglofauna, threatened species, Barrow Island

\section{INTRODUCTION}

Subterranean fauna has been the focus of many environmental surveys in recent years in Western Australia. This has mostly been driven by increasing development activity and the legislative requirement to assess potential impacts on populations of subterranean animals (EPA 2003). Most survey effort has focused on the north-west of the state, including Barrow Island; a karstic limestone island located approximately $170 \mathrm{~km}$ to the north-east of Cape Range (Figure 1).

Resource development commenced on Barrow Island in 1964 with active oil exploration and production. This has continued to the present day, but additional development has occurred on the island since 2009 with construction of onshore natural gas processing facilities (Chevron 2006).

Barrow Island is also internationally recognised 


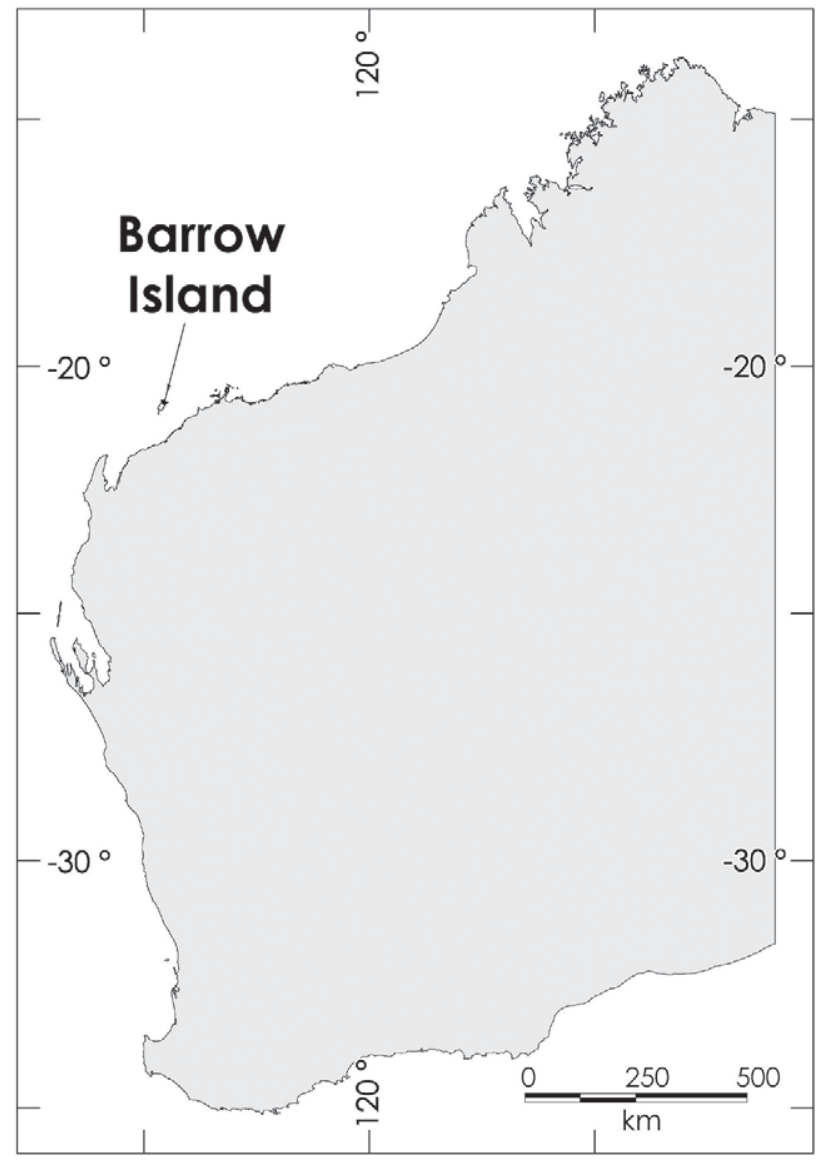

FIGURE 1

Location of Barrow Island in comparison to mainland Western Australia.

for its subterranean fauna biodiversity values (Burbidge 2004), and sampling for both stygobitic and troglobitic fauna has taken place on the island since 1991 (Humphreys 2001). Stygobitic fauna, or stygofauna, are those fauna inhabiting interstices and voids in groundwater, sometimes occurring very close to the surface (Humphreys 2001). Troglobitic fauna are fauna living in caves, cavities and fractured rock between the water table and the superficial soil layer, depending on the availability of habitat space.

Humphreys (2001) summarised the then current state of knowledge of both the troglobitic and stygobitic components of the fauna of Barrow Island. Just over a decade later, this review provides an updated account of the island's subterranean fauna and our current understanding of species' distributions compared to records published in 2001.

\section{FIELD SAMPLING METHODOLOGY}

Barrow Island has been sampled for stygofauna a total of 11 times between 2002 and 2012, and seven times for troglobitic fauna over the same period.

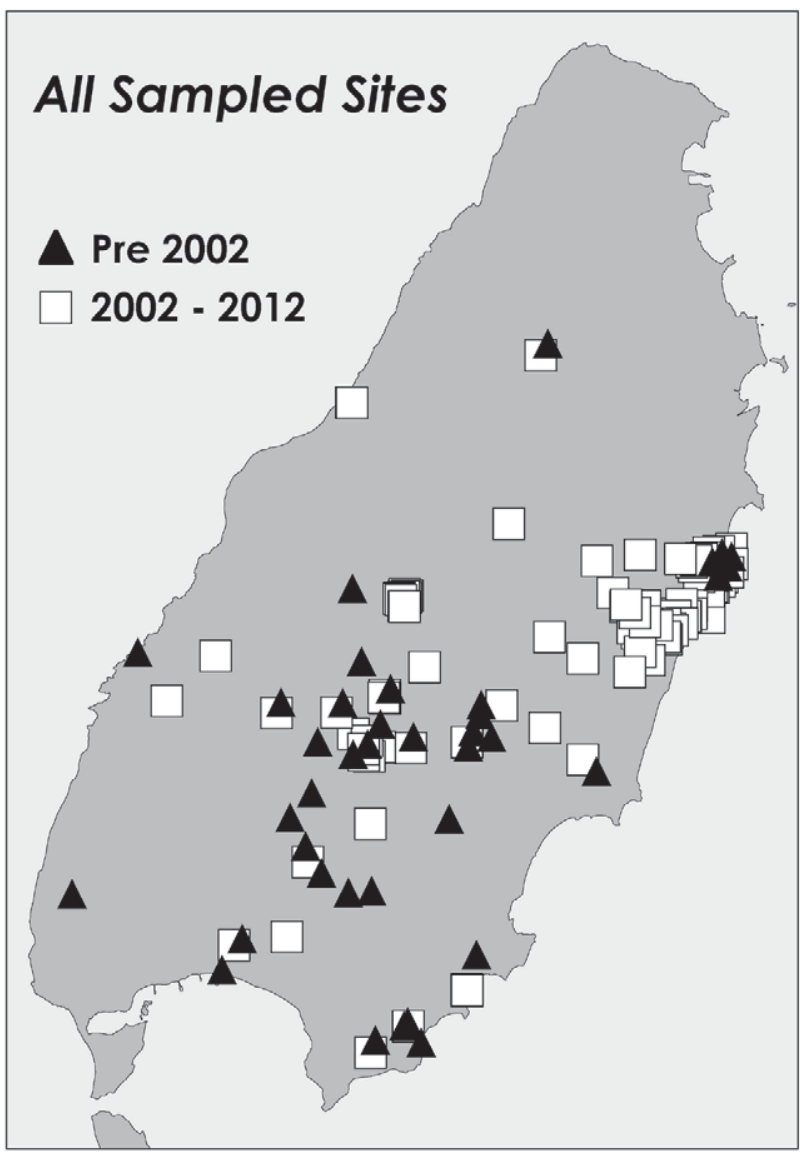

FIGURE 2

Location of subterranean fauna sampling sites on Barrow Island from prior to 2002 and between 2002 and 2012.

The primary focus of these surveys was to collect data to support the environmental assessment of the proposed Gorgon Gas Treatment Plant, which started construction in 2009. Humphreys (2001) reported on an earlier seven phases completed between 1991 and 1999, which documented the findings of cave exploration, habitat and biophysical data measurement, and subterranean fauna baseline sampling. The methods employed in these earlier pre-2002 phases are presented by Humphreys (2001) and only more recent field work is addressed here.

This latter sampling on Barrow Island mostly utilised existing drill holes installed for the operational oilfield or for the assessment of the natural gas plant. Some of the bores used in the eastern part of the island were installed specifically for subterranean fauna sampling. Sampling followed methods equivalent to those outlined in the Western Australian Environmental Protection Authority (EPA) Guidance Statement No. 54 (EPA 2003) and EPA draft Technical Appendix No. 54a (EPA 2007). This has largely comprised sampling with plankton haul nets for stygofauna and the use of leaf litter colonisation traps for 
troglofauna. The spatial extent covered by pre-2002 and more recent sample sites is shown in Figure 2. A combined total of 118 sites have been sampled for subterranean fauna to date, though the northern and south-western portions of the island remain poorly sampled.

Determinations of collected specimens were completed using either morphological or molecular techniques, depending on taxa. Many specimens were unable to be assigned to a species due to specimen condition (damaged or juvenile). Where possible, specimens were identified on the basis of morphological characters by examination under dissecting and compound microscopes; dissection, slide-mounting and staining of key diagnostics features; comparisons to reference specimen collections (including side-by-side comparison with Western Australian Museum holotypes where appropriate); and the use of published and unpublished taxonomic keys where available.

Molecular analysis and mitochondrial cytochrome oxidase I (COI) barcoding of select specimens of stygal Amphipoda and Isopoda, as well as troglobitic Thysanura, was undertaken by Helix Molecular Solutions Pty Ltd. That work was commissioned by Chevron Australia, specifically the Gorgon Project, for environmental approval and compliance purposes (Helix Molecular Solutions 2012), as were earlier, related molecular studies undertaken by the School of Animal Biology at the University of Western Australia (Finston 2007). The amphipod lineages defined by Finston (2007) are used here as species-level taxon equivalents. Nominal amphipod species from that study were in turn determined by reference to the review of divergence in species pairs completed by Hebert et al. (2002). The mean percentage sequence divergence between species of crustaceans was higher than the average for all taxonomic groups, averaging 15.4\% (Hebert et al., 2002). The Barrow Island amphipod lineages treated as separate species by the Finston (2007) study differed by 15$36 \%$ sequence divergence.

Given the age of some of the material from Barrow Island, and that preservation methods have varied over time, some specimens have only been identified by morphological methods and other more recent collections by molecular techniques. It is therefore possible that some specimens with different determination methods actually represent the same species, but it has not been possible to reconcile this with the available material. This is mostly a consideration for the Amphipoda, where earlier morphological taxonomic appraisals were followed by later molecular studies, with the Oniscidea affected to a minor degree. We have treated this issue conservatively here and our primary approach is to report all currently known taxa, whether morphological or molecular, but also to provide a lower species richness in the event that all molecular taxa are in fact representatives of currently described morphological species.

\section{STYGOFAUNA}

Since subterranean fauna sampling began, 63 stygal species have been collected from Barrow Island, representing 12 orders. The fauna is strongly numerically dominated by the Crustacea, but some specimens have also been collected from the Annelida and Chordata. Prior to 2002, the known stygofauna of the Island comprised 25 species, with over half belonging to the order Amphipoda. This number has now been more than doubled, with a further 38 species of stygofauna having been identified from Barrow Island using morphological and molecular identification techniques.

Eleven of the new taxa added since 2001 were identified using molecular techniques but are yet to be formally described. Ten of these molecular species belong to the order Amphipoda, comprising three undescribed species belonging to the family Bogidiellidae, six species of Melitidae and one Paramelitidae. An additional species, likely belonging to the stygal isopod suborder Oniscidea, was also discovered using molecular analysis (Helix 2012).

The decapod crustacean Stygiocaris stylifera Holthuis, 1960 (family Atyidae) has been the single most commonly recorded stygal species from the Island, with 440 individuals collected in total since 1991, accounting for over $21 \%$ of all stygal specimens. Prior to 2002, S. stylifera was known from 16 sites on Barrow Island, including Ledge Cave (site 6B1 of Humphreys (2001)). S. stylifera has since been collected from 19 sites, just two of which overlap with the original 16 locations (Figure 2). We have therefore increased the known distribution of the species by 17 locations since 2002, and the species has been recorded in reasonable abundance ( $n=10$ or more individuals) from 13 of the 33 known sites. It is clearly a widespread and common taxon across Barrow Island.

A total of 23 amphipod species have now been collected on Barrow Island, comprising the 13 morphologically identified species collected prior to 2002 and 10 molecular lineages (species equivalents for the purposes of this paper) identified between 2002 and 2012. The relative abundance of amphipod taxa appears to vary significantly: nine of the 13 species identified morphologically, and four of the 10 identified by DNA sequencing, are known only from single records. By contrast, the undescribed species Nedsia sp. 1 was recorded 306 times from 46 sites during sampling from 2002 onwards. Should all the molecular species prove to equate to taxa 


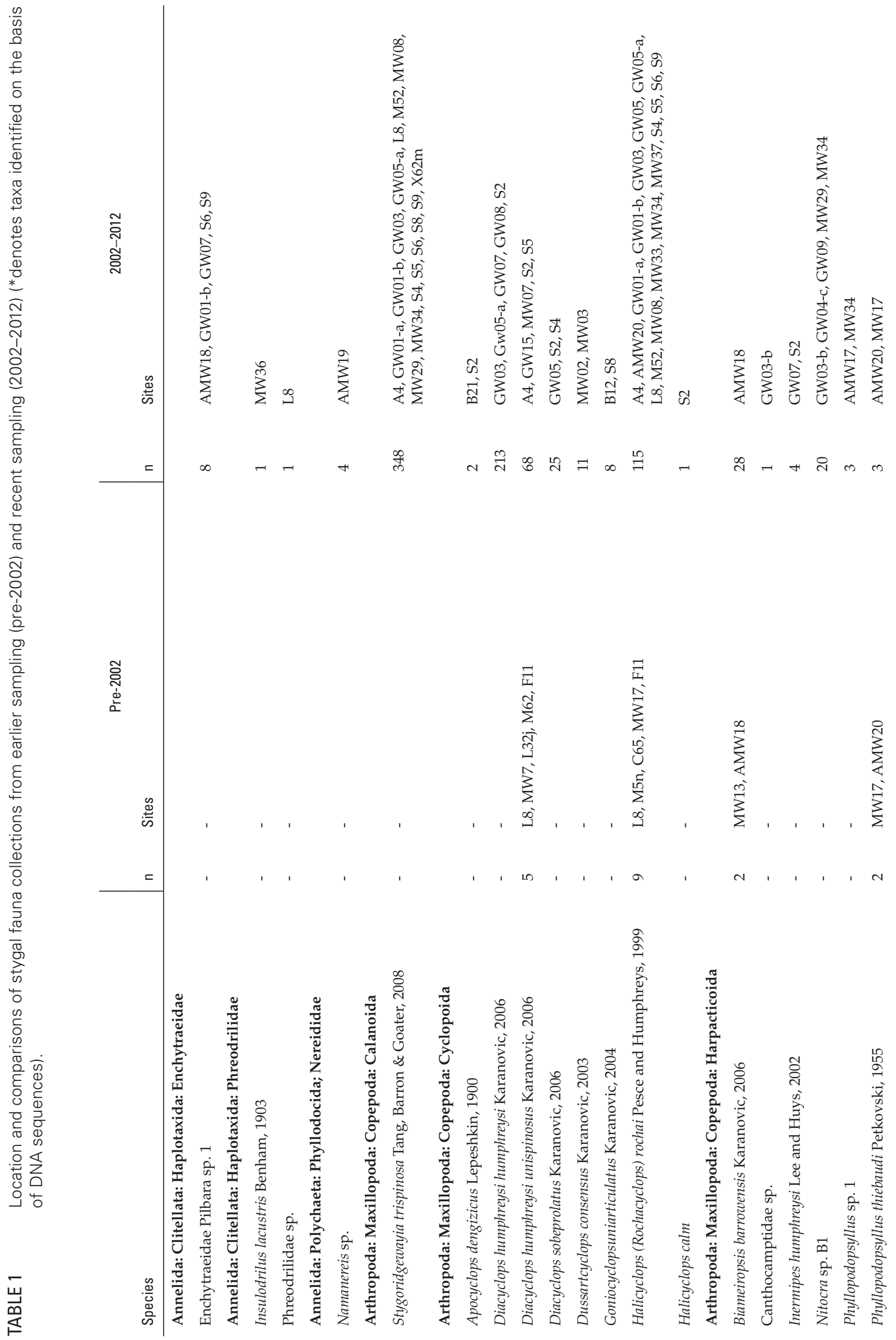




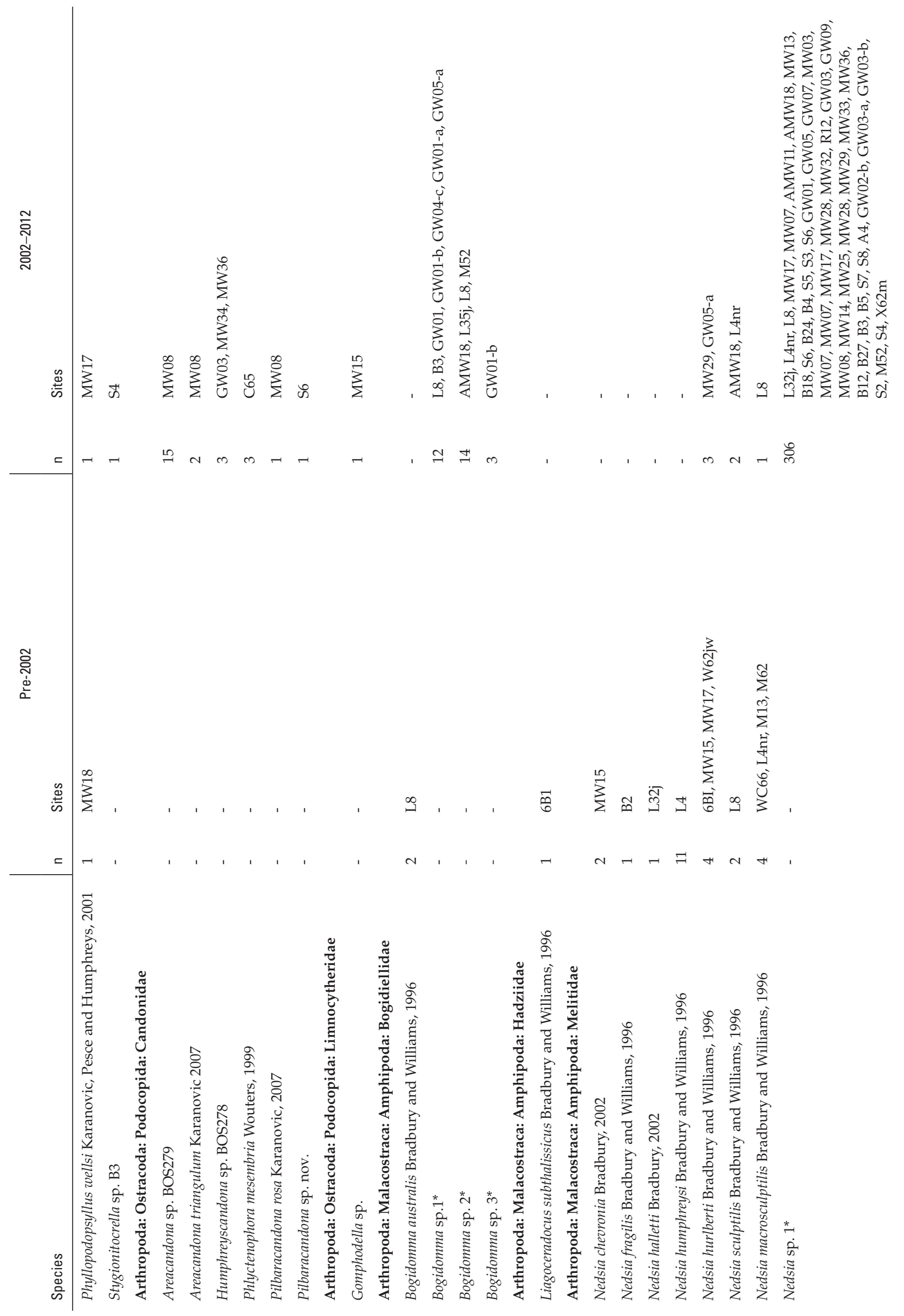




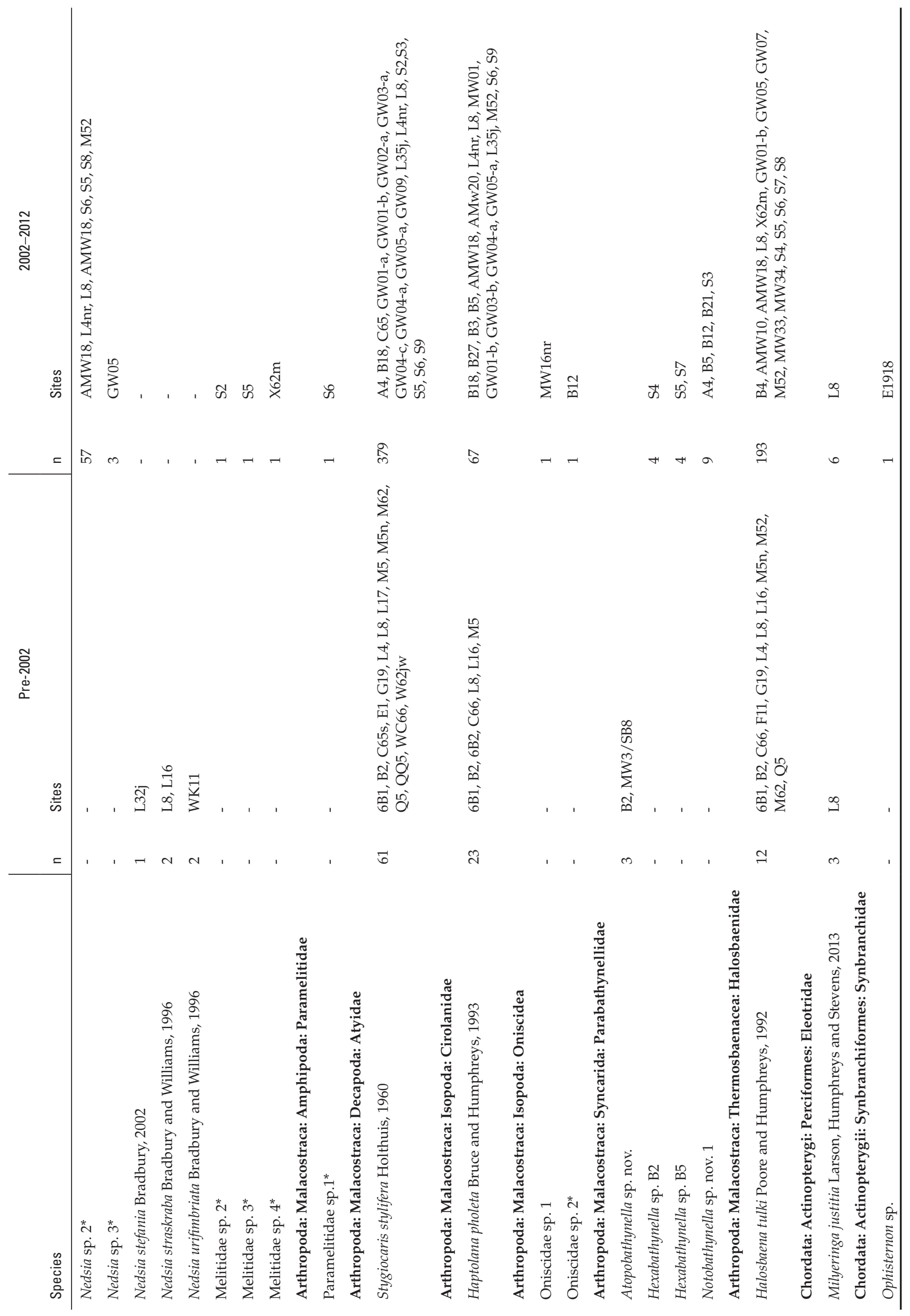


previously described from morphology, the total species count for this taxonomic group would decrease to 14 (one molecular taxon is clearly a new species as the only representative of its family; Paramelitidae sp. 1 (Table 1)).

Three Copepoda orders have been recorded on Barrow Island to date. Two of the orders, Cyclopoida and Harpacticoida, were known from the island prior to 2002, but 11 new taxa belonging to these orders have since been detected. Stygoridgewayia trispinosa Tang, Barron and Goater, 2008 (family Ridgewayiidae), a member of the third order, Calanoida, has been regularly recorded since 2002, occurring at 16 sites. A further six species of cyclopoid copepod (family Cyclopidae) have also been collected, in addition to the species Halicyclops rochai Pesce and Humphreys, 1999 and Diacyclops humphreysi unispinosus Karanovic, 2006, which were known previously from the island. Four species of harpacticoid copepod were also collected in addition to the three species known prior to 2002. Two of these were from the family Ameiridae (Biameiropsis barrowensis Karanovic, 2006 and Inermipes humphreysi Lee and Huys, 2002) and two from the family Tetragonicepsidae (Phyllopodopsyllus thiebaudi Petkovski, 1955 and Phyllopodopsyllus wellsi Karanovic, Pesce and Humphreys, 2001). The four harpacticoids represent currently undescribed taxa.

Three species of isopod have now been recorded from Barrow Island. The species Haptolana pholeta Bruce and Humphreys, 1993 (family Cirolanidae) is by far the most common and has been recorded from 23 sites with 67 specimens collected in total. The species was previously known from Barrow Island (Humphreys 2001a), but its distribution has been substantially expanded across the southern half of the island in the last decade (Figure 2). The remaining two oniscid species are apparently at low frequency and have only been recorded from singleton records. Oniscidea sp. nov. 1 was identified morphologically and Oniscidea sp. nov. 2 was identified using molecular techniques. It is currently unclear if the two specimens actually represent the same taxon, as Oniscidea sp. nov. 1 failed to yield a sequence, and they have been conservatively been treated as two taxa here (Table 1).

The syncarid family Parabathynellidae has also now been recorded from 10 sites on Barrow Island compared to just two in 2002 (Figure 2). This includes the detection of three additional species, bringing the total species richness of this family to four (Table 1). The distributions of three relatively common stygal species on the island have also been expanded: Haptolana pholeta, Halosbaena tulki Poore and Humphreys, 1992 (family Halosbaenidae) and Stygiocaris stylifera have minimum distributions of
$83.4,130.6$ and $125.6 \mathrm{~km}^{2}$ respectively, updated from $46.6,47.9$ and $85.4 \mathrm{~km}^{2}$ respectively (Figure 2).

Two stygal vertebrate species have been recorded to date on Barrow Island: the Blind Cave Gudgeon, Milyeringa justitia (Larson et al. 2013), and a Cave Eel. Individuals of the Blind Gudgeon have been recorded relatively rarely during past sampling on Barrow Island and only from two sites, with most records from well L8, located in the interior of the island $\left(20^{\circ} 49^{\prime} 2.31^{\prime \prime} \mathrm{S}, 11^{\circ} 23^{\prime} 41.98^{\prime \prime} \mathrm{E}\right)$ (Figure 2). Six individuals of $M$. justitia have been collected since 2002.

The record of the stygal eel, Ophisternon sp. (generic assignment unconfirmed), was made in 2009 using unconventional methods. Seismic testing on the island brought the specimen to the surface, where it was photographed, but the carcass was returned to the water table and not available for taxonomic confirmation. The eel was recorded from seismic testing site E1918 (2041'22.00"S, $\left.115^{\circ} 26^{\prime} 33.89^{\prime \prime} \mathrm{E}\right)$. A vouchered specimen would be required to determine if this represents the same species as those previously collected on Cape Range and at Bungaroo Creek in the west Pilbara region (Ophisternon candidum Mees 1962 (Synbranchidae)). Given the wide range of $O$. candidum in stygal ecosystems in the Pilbara, the Barrow Island blind eel is taken to be $O$. candidum for the purposes of conservation status (Larson et al. 2013).

Table 1 provides a full account of the current known stygobitic fauna of Barrow Island at 63 taxa, or a minimum of 53 species if all molecular lineages equate to species previously recognised from morphology.

\section{TROGLOBITIC FAUNA}

Prior to 2002, sampling for troglofauna on Barrow Island involved the use of active searching within cave systems or specimens collected as by-catch during stygofauna sampling. Given this, only six species of troglobitic fauna were confirmed from Barrow Island when reviewed by Humphreys (2001). Sampling on the island since this time has centred on the use of leaf litter filled colonisation traps, which are placed at intervals within drillholes installed for subterranean fauna sampling, geotechnical assessment or other purposes. These traps remain in place for a minimum of six weeks, which allows for colonisation by subterranean fauna. This sampling method has resulted in a further 13 species being recorded from the island for a total of 19 known troglobite taxa. This includes members of the Arachnida, Insecta, Myriapoda and Crustacea.

The most common and widespread troglobite on Barrow Island is the schizomid Draculoides bramstokeri Harvey and Humphreys, 1995 (family 

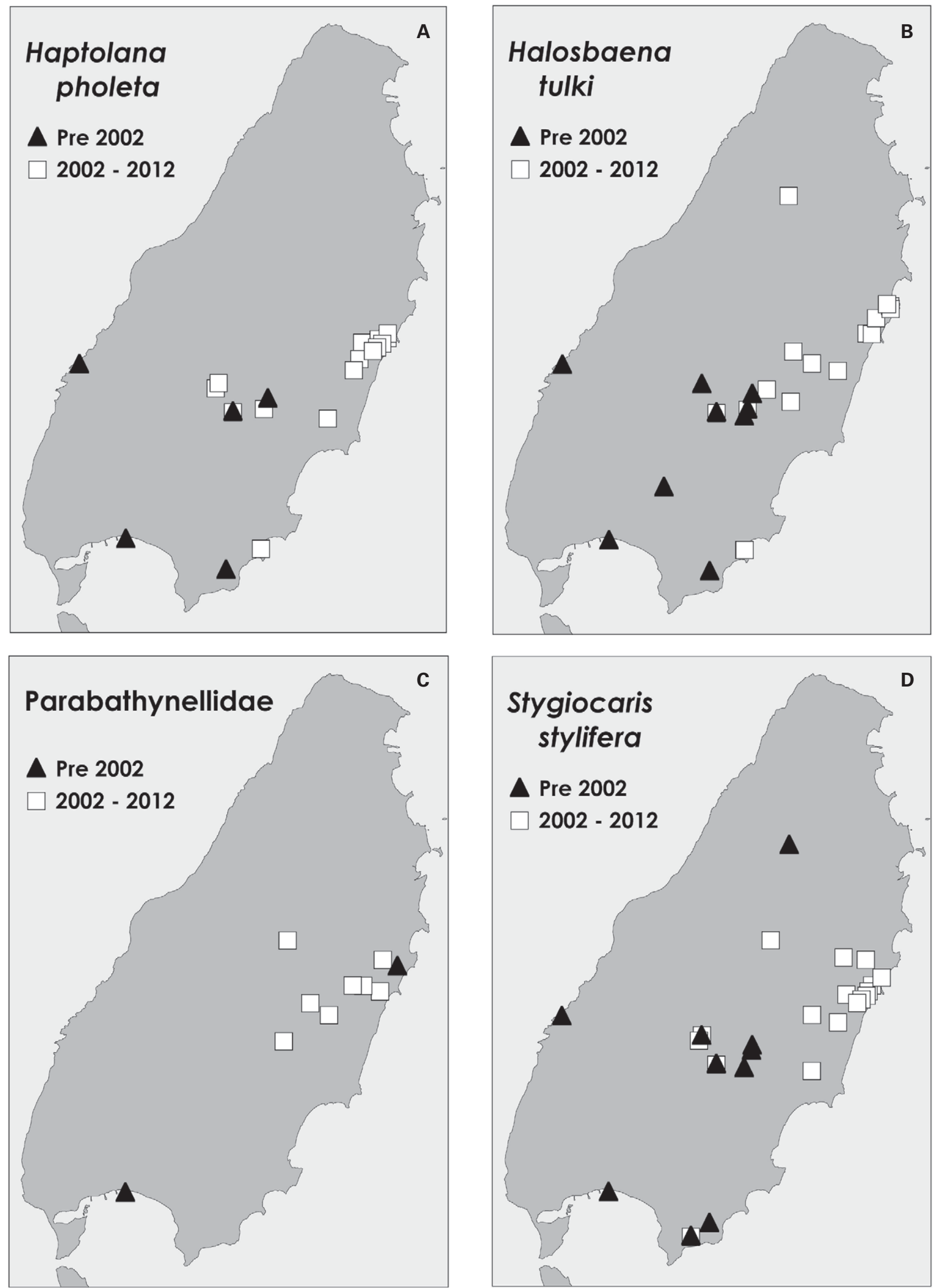

FIGURE 3

Changes in recorded distributions of selected stygobitic species and families on Barrow Island between 2002 and 2012. 


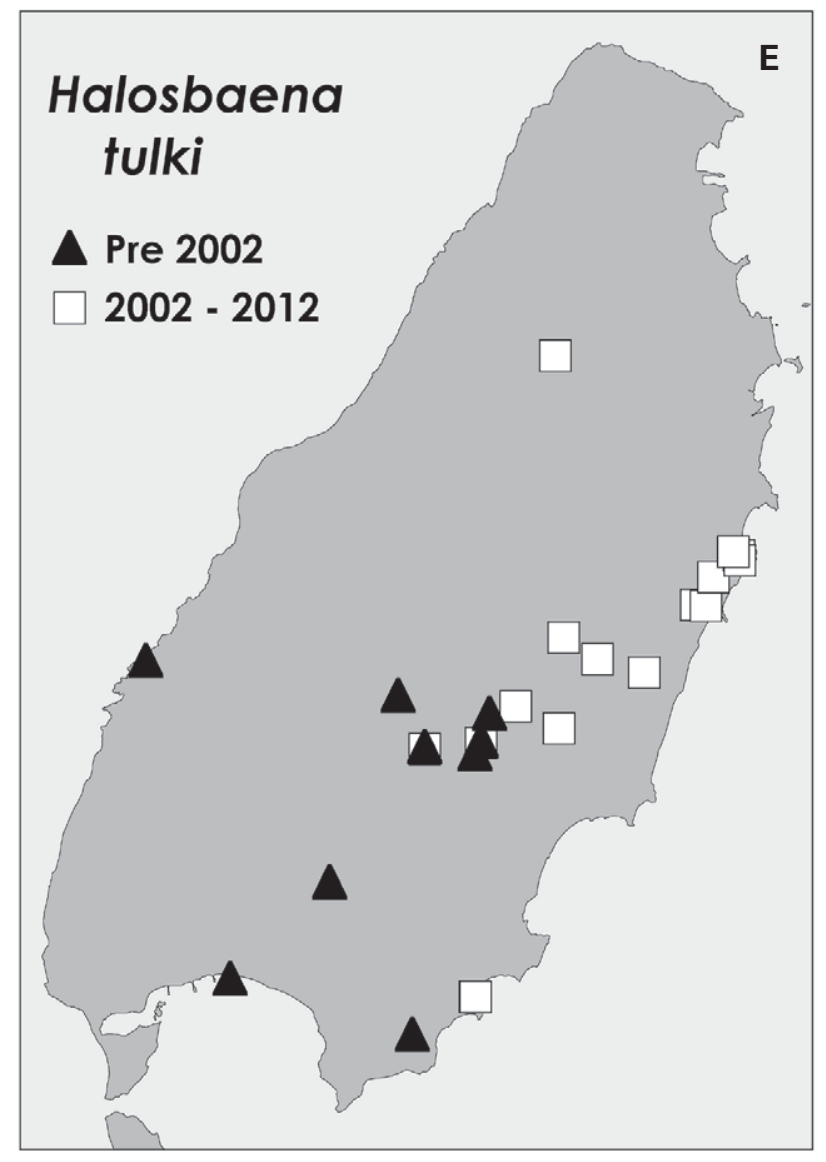

Hubbardiidae). Draculoides bramstokeri was known from seven locations in the west of the island prior to 2002, including Ledge Cave (site 6B1). Since that time, the species has been shown to be more widely distributed, occurring in 27 of the 31 sites where troglobites have been recorded across the island since 2002 (Figure 3). Draculoides bramstokeri now has an inferred distribution of at least $73.4 \mathrm{~km}^{2}$ across the island based on all known records.

Several new arachnid species have been revealed from recent sampling including two species of pseudoscorpion, Ideoblothrus nesotymbus Harvey and Edward, 2007 (family Syarinidae) and Tyrannochthonius garthhumphreysi Edward and Harvey, 2008 (family Chthoniidae), and two new species belonging to the spider family Gnaphosidae. Further, three undetermined specimens of the infrequently collected arachnid order Palpigradi were collected from two sites in the east of the island (Table 2).

Six myriapod species have been collected from Barrow Island, including a single troglobitic species from the order Polydesmida (family Pachybolidae) Speleostrophus nesiotes Hoffman, 1994. This species was recorded from one study site (6B1) prior to 2002, however additional sampling has now demonstrated that the species occurs across a much larger proportion of the island, with a minimum area of occupancy of $30.8 \mathrm{~km}^{2}$ (Figure 3). Insufficient information is available to determine the troglobitic status of the indeterminate taxon Haplodesmidae sp., which is currently only known from a single site (GW05-b) on the east of the island.

The troglobitic cockroach Nocticola sp. nov. 1, which was historically only known from site 6B1 (Ledge Cave) on the west side of the island, has now been collected from three locations in the east (Figure 3).

Two terrestrial crustacean taxa have been collected from subterranean habitats on Barrow Island: an undetermined member of the Isopoda suborder Oniscidea known from Ledge Cave pre-2002; and a second isopod taxon (family Philosciidae), which is also currently undescribed but represented by specimens from six sites in the western part of the island (Table 2).

Molecular analysis was utilised to provide species confirmation for specimens belong to the hexapod order Thysanura, which have been collected from three sites on Barrow Island. This analysis revealed the presence of two troglobitic species collected from three locations, Trinemura sp. nov. 1 from sites B11 and S9, and Trinemura sp. nov. 2 from site S2 (family Nicoletiidae; Helix Molecular Solutions 2011) (Table 2).

Table 2 provides a full account of the currently known troglobitic fauna of Barrow Island.

\section{DISCUSSION}

Repeated systematic sampling over recent years has substantially increased the documented subterranean diversity of Barrow Island. The increase in distribution has been made possible by the presence of new bore holes drilled for site assessment that have enabled sampling of the subterranean environments over a greater part of the island. The richness of the recorded subterranean fauna has more than doubled from the earlier account of Humphreys (2001), from 31 stygobitic and troglobitic species at that time to 82 taxa now known from the island. Allowing for possible duplication between molecular and morphologically recognised stygal species, the minimum subterranean assemblage for the island stands at 72 taxa.

It is worth noting that the last decade of work has mostly sampled the same set of sites on the island, and it is likely that considerably more species remain to be recorded from other parts of Barrow Island. This pattern of significant increases in documented subterranean biodiversity in the past decade has also been documented for other parts of Western Australia, particularly the Yilgarn, Pilbara and Cape Range (Eberhard et al. 2005, Harvey 

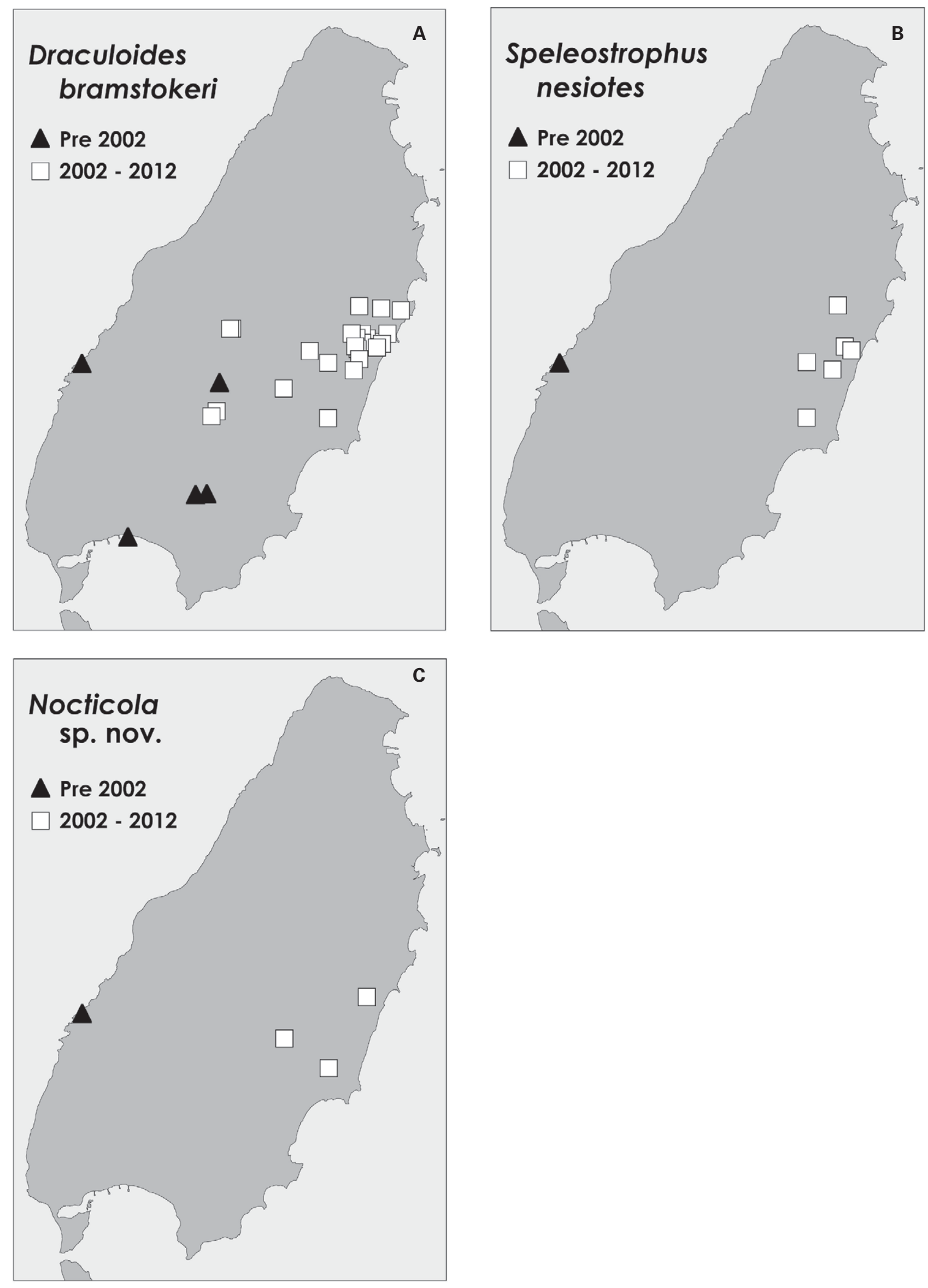

FIGURE 4 


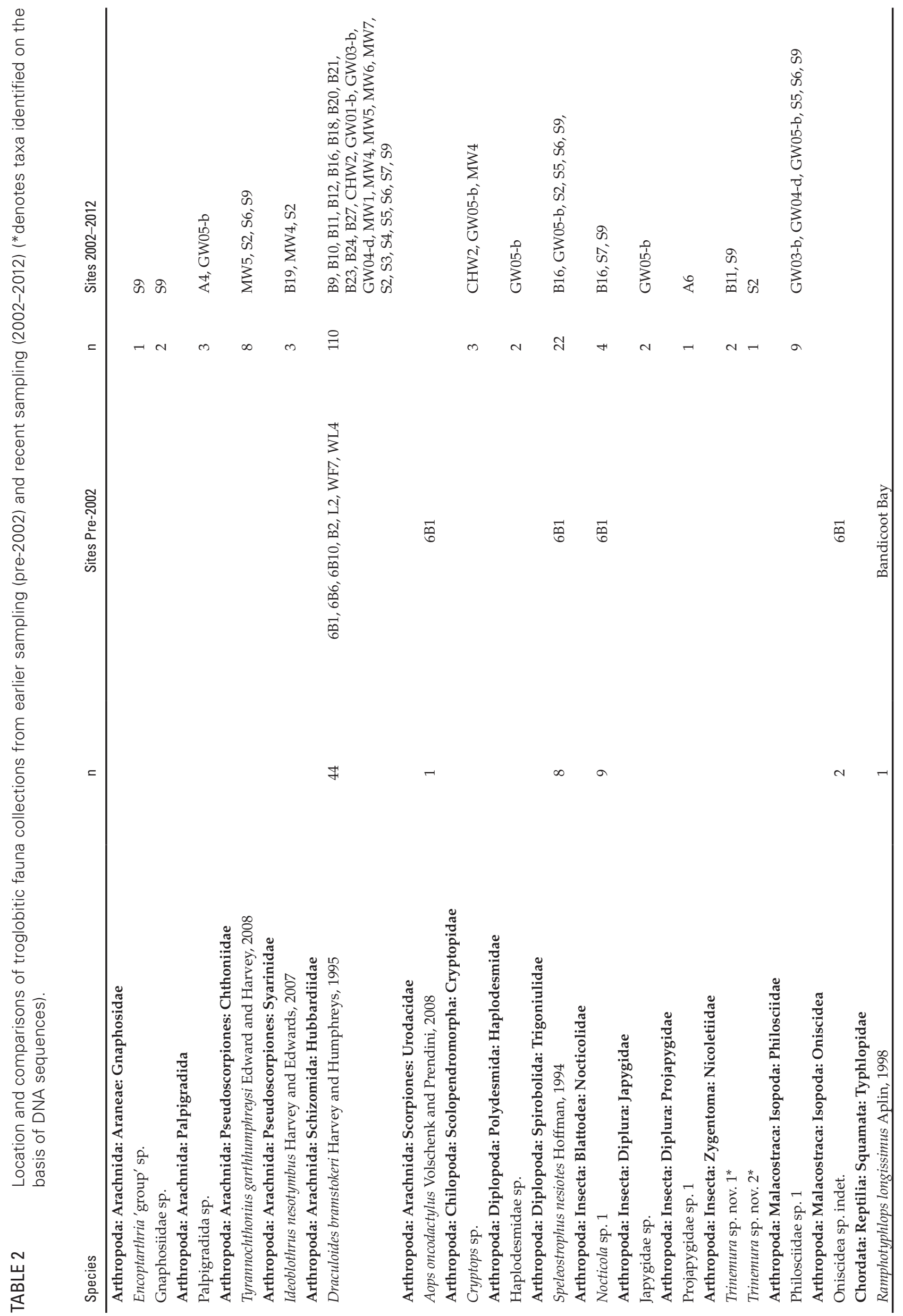




\begin{tabular}{lcc} 
Species (Common Name) & Federal & State \\
\hline Troglobitic fauna & - & Vulnerable \\
Draculoides bramstokeri (Barrow Island Draculoides) & Vulnerable & Vulnerable \\
Speleostrophus nesiotes (Barrow Island Millipede) & & Vulnerable \\
Stygobitic fauna & Vulnerable & Vulnerable \\
Milyeringa veritas (justitia) (Blind Cave Gudgeon) & Vulnerable & Vulnerable \\
Ophisternon candidum (Cave Eel) & - & Vulnerable \\
Bogidomma australis (Barrow Island Bogidomma Amphipod) & - & Vulnerable \\
Liagoceradocus subthalissicus (Barrow Island Liagoceradocus) & - & Vulnerable \\
Nedsia fragilis & - & Vulnerable \\
Nedsia humphreysi & - & Vulnerable \\
Nedsia hurlberti & - & Vulnerable \\
Nedsia macrosculptilis & - & Vulnerable \\
Nedsia sculptilis & - & Vulnerable \\
Nedsia straskraba & - & \\
Nedsia urifimbriata & - & \\
\hline
\end{tabular}

et al. 2011). Barrow Island was isolated from the Pilbara and Cape Range as recently as the Holocene (Humphreys 2001). In both these latter areas there is still emerging information placing the region at or near the most biodiverse subterranean fauna globally, after only three decades of study. Together, these areas support significant continental and anchialine stygofauna in carbonate, fractured rock and alluvial geologies, and troglofauna in alluvial, carbonate, fractured rock and pisolite geologies. The stygofauna, anchialine fauna and troglofauna have biogeographies strongly linked, respectively, with Gondwana, the Tethys and rainforests (Harvey et al. 2008; Humphreys 2008, 2012; Page et al. 2008).

In addition to expanding the subterranean assemblage, recent data have substantially expanded the known distributions of several subterranean species already known from Barrow Island in 2002. Given the increases to virtually island-wide distributions in Draculoides bramstokeri, Stygiocaris stylifera and Halosbaena tulki, and the cavernous nature of karstic habitat of Barrow Island (Humphreys 2001), it is possible that further survey effort could reveal that many other subterranean taxa have wider distributions than currently documented.

Three troglobitic species known from Barrow prior to 2002 have not been recorded since that time: the scorpion Aops oncodactylus Volschenk and Prendini, 2008, the blind snake Ramphotyphlops longissimus Aplin, 1998 (family Typhlopidae) and at least one unidentified species of Oniscidea.
Similarly, the Blind Gudgeon Milyeringa justitia is still primarily only known from sampling locations central to the island, where the freshwater lens is thickest (Figure 3; Humphreys (2001)). It is possible that these taxa represent species that are locally restricted within the island, but the distributional records are confounded by sampling artefacts inherent to borehole casing. Given the relative size of $A$. oncodactylus and $R$. longissimus (Wilson and Swan 2003) it is possible that the down-hole sampling methods (and/or borehole construction) used in recent times are not suitable for recording larger body size fauna. Colonisation traps filled with leaf litter material and smaller slotting in drillhole casings may prevent the entrance of larger fauna and skew records toward specimens with smaller body forms. Many holes drilled recently on Barrow Island for water monitoring purposes have $50 \mathrm{~mm}$ diameter casing with less than $0.5 \mathrm{~mm}$ slots, which could exclude larger species from collection.

There are also some stygal species known from the island prior to 2002 that have not been recorded since. These all belong to the Amphipoda, with most from the family Melitidae, and single species from the Hadziidae and Bogidiellidae. It is currently unclear if these species are actually taxonomically distinct from those collected in the later phases of sampling or if this is a function of changes in methodology over the past decade. Molecular analysis has largely been employed to delineate taxa in recent years, whereas the pre-2002 specimens were largely determined morphologically. As noted earlier, it is 
possible that some of the genetic lineages collected recently correspond to past described species, but sequencing of this historical material would be required to rationalise identifications in this group.

Each of the species identified here as Haptolana pholeta, Stygiocaris stylifera and Halosbaena tulki has unpublished molecular data that suggest that each may represent a cryptic complex (T.J. Page, M. Baratti and W.F. Humphreys, pers. comm.). Resolution of this would likely further increase the species count for the island.

The biology and ecology of the fauna is unknown save for what can be inferred from similar taxa in epigean, often northern hemisphere, studies. The energy source for the subterranean fauna, as indicated by stable isotope ratio analysis, is largely consistent with carbon fixation by plants with $\mathrm{C} 3$ and $\mathrm{C} 4$ photosynthesis pathways but in places the $\delta 13 C$ signature is light and it has been suggested that this may reflect chemosynthetic energy production associated with the petroleum deposits (Humphreys 2001), as found in the Edwards Aquifer, Texas (Hutchins et al. 2011) and the Upper Floridan Aquifer (Opsahl and Chanton 2006).

Many of the subterranean species on Barrow Island, both troglobitic and stygobitic, are listed as vulnerable and specially protected under the Western Australian Wildife Conservation Act 1950. However, only two species, the stygal vertebrate Milyeringa veritas (justitia), and Ophisternon candidum are listed as Vulnerable under the Federal Environment Protection and Biodiversity Conservation Act 1999. A summary of these species of conservation significance is displayed in Table 3.

There is still outstanding work to be completed on the fauna of Barrow Island, particularly with regards to reconciling morphological and molecular taxa amongst the Amphipoda. While some of this could be undertaken with available material, further specimens will probably be required to refine the known total fauna of the island. As new species are also consistently being collected with the ongoing sampling, and many parts of the island remain poorly surveyed, it is too early to accurately estimate the level of subterranean diversity of Barrow Island. The available data suggest that the fauna of the island may number in the hundreds of species, many of which are endemic, confirming its status as internationally significant for subterranean biota.

\section{ACKNOWLEDGEMENTS}

The cost of field work to collect specimens over the past decade, and the subsequent identification of material, was met by Chevron Australia, for which we are grateful. Chevron Australia scientists, particularly Dorian Moro, Eamon Dorricott and
Andrew Smith, contributed to sampling design, supported and promoted research initiatives and provided valuable logistical support during field surveys. We also acknowledge Volker Framenau, Stuart Halse, Jane McRae, Adrian Pinder and Russ Shiel, who completed morphological identification of some of the specimens discussed in this paper. Terrie Finston and Yvette Hitchen sequenced the amphipod and thysanuran fauna collected from the island. Many zoologists assisted the authors over the last decade of field sampling, including Roy Teale, Michael Greenham, Lee Mould, Karen Edward, Jessica Cairnes, Penny Brooshooft, Nicola Watson and Sylvie Schmidt. We also thank Paul Sawers and Kylie Webster for preparing the Figures for this paper. This paper was improved by referee comments received from Stefan Eberhard, Tim Moulds and Stefano Taiti.

\section{REFERENCES}

Burbidge, A.A. (2004). Threatened Animals of Western Australia. Department of Conservation and Land Management: Perth.

Chevron (2006). Final Environmental Impact Statement/ Response to Submissions on the Environmental Review and Management Programme for the Proposed Gorgon Development. Chevron: Australia.

Eberhard, S.M., Halse, S.A. and Humphreys, W.F. (2005). Stygofauna in the Pilbara region, Northwest, Western Australia; a review. Journal of the Royal Society of Western Australia 88: 167-176.

EPA (2003). EPA Guidance Statement No. 54: Sampling of subterranean fauna in groundwater and caves. Environmental Protection Authority: Perth, Western Australia.

EPA (2007). EPA Guidance Statement No. 54a: Sampling Methods and Survey Considerations for Subterranean Fauna in Western Australia. Environmental Protection Authority: Perth, Western Australia.

Finston, T.L. (2007). Molecular diversity in amphipods from Barrow Island, Western Australia. Unpublished report prepared for Chevron Australia, University of Western Australia, Crawley.

Harvey, M.S., Berry, O., Edward, K.L. and Humphreys, G. (2008). Molecular and morphological systematics of hypogean schizomids (Schizomida: Hubbardiidae) in semiarid Australia. Invertebrate Systematics 22: 167-194.

Harvey, M.S., Rix, M.G., Framenau, V.W., Hamilton, Z.R., Johnson, M.S., Teale, R., Humphreys, G., and Humphreys, W.F. (2011). Protecting the innocent: studying short-range endemic taxa enhances conservation outcomes. Invertebrate Systematics 25: 1-10.

Hebert, P.D.N., Ratnasingham S., and deWaard, J.R. (2002). Barcoding animal life: cytochrome c oxidase subunit 1 divergences among closely related species. Proceedings of the Royal Society of London, B (Supplement) 270: S96-S99.

Helix Molecular Solutions (2011). Report on the molecular systematics of Thysanura from Barrow Island. Unpublished report prepared for Biota Environmental 
Sciences, Helix Molecular Solutions.

Helix Molecular Solutions (2012). Report on the molecular systematics of Amphipoda from Barrow Island - Phase 5. Unpublished report prepared for Biota Environmental Sciences, Helix Molecular Solutions.

Humphreys, W.F. (2000). Background and glossary. In: Wilkens, H., Culver, D.C. and Humphreys, W.F. (eds), Ecosystems of the World: Subterranean Ecosystems: pp. 3-14. Elsevier Science: Amsterdam.

Humphreys, W.F. (2001). The subterranean fauna of Barrow Island, northwestern Australia, and its environment. Memoires de Biospeologie (International Journal of Subterranean Biology) 28: 107-127.

Humphreys, W.F. (2008). Rising from down under: developments in subterranean biodiversity in Australia from a groundwater fauna perspective. Invertebrate Systematics 22: 85-101.

Humphreys, W.F. (2012). Diversity patterns in Australia. In: White, W.B. and Culver, D.C. (eds), Encyclopedia of Caves, $2^{\text {nd }}$ Edition: 203-219. Academic Press: San Diego.

Hutchins, B., Schwartz, B., and Engel, A. (2011). Hydrogeologic and geochemical controls on nutrient availability and food web dynamics in the biodiverse karstic Edwards Aquifer, TX, USA. Poster \#31051 Ecological Society of America Meeting, Texas, 11 August 2011.

Larson, H.K., Foster, R., Humphreys, W.F., and M.L. Stevens (2013). A new species of the blind cave gudgeon Milyeringa (Pisces: Gobioidei, Eleotridae) from Barrow Island, Western Australia, with a redescription of $M$. veritas Whitley. Zootaxa 3616: 135-150.

Opsahl, S.P. and Chanton, J.P. (2006) Isotopic evidence for methane-based chemosynthesis in the Upper Floridan aquifer food web. Oecologia 150: 89-96.

Page, T.J., Humphreys, W.F., and Hughes, J.M. (2008). Shrimps down under: evolutionary relationships of subterranean crustaceans from Western Australia (Decapoda: Atyidae: Stygiocaris). PLoS ONE 3(2): e1618, 1-12.

Wilson, S., and Swan, G. (2003). A complete guide to reptiles of Australia. New Holland Publishers (Australia) Pty Ltd: Chatswood.

MANUSCRIPT RECEIVED 23 MAY 2012; ACCEPTED 23 SEPTEMBER 2013. 